\title{
Inflammatory cytokine and microRNA responses of primary human dendritic cells cultured with Helicobacter pylori strains
}

\section{Anaïs Hocès de la Guardiaa,2t, Cathy Staedel ${ }^{3,4+}$, Itidal Kaafarany ${ }^{1,2}$, Aurélien Clément ${ }^{1,2}$, Claire Roubaud Baudron ${ }^{1,2,5}$, Francis Mégraud ${ }^{1,2}$ and Philippe Lehours ${ }^{1,2 *}$}

1 Bacteriology Laboratory, Université Bordeaux, Bordeaux, France

2 Institut National de la Santé et de la Recherche Médicale, U853, Bordeaux, France

${ }^{3}$ ARNA Laboratory, Université Bordeaux, Bordeaux, France

${ }^{4}$ Institut National de la Santé et de la Recherche Médicale, U869, Bordeaux, France

${ }^{5}$ Pôle de Gérontologie Clinique, CHU de Bordeaux, Bordeaux, France

\section{Edited by:}

Abhay Satoskar, The Ohio State

University, USA

\section{Reviewed by:}

Bernard Arulanandam, University of

Texas as San Antonio, USA

Heinrich Korner, Menzies Research

Institute Tasmania, Australia

*Correspondence:

Philippe Lehours, Bacteriology Laboratory, Université Bordeaux

Segalen, Institut National de la

Santé et de la Recherche Médicale,

rue Léo Saignat, U853, F-33076

Bordeaux, France

e-mail:philippe.lehours@

u-bordeaux2.fr

t'These authors have contributed

equally to this work.
Primary human dendritic cells (DC) were used to explore the inflammatory effectors, including cytokines and microRNAs, regulated by Helicobacter pylori. In a $48 \mathrm{~h}$ ex-vivo co-culture system, both H. pylori B38 and B45 strains activated human DCs and promoted a strong inflammatory response characterized by the early production of pro-inflammatory TNF $\alpha$ and IL- 6 cytokines, followed by IL-10, IL-1 $\beta$, and IL-23 secretion. IL-23 was the only cytokine dependent on the cag pathogenicity island status of the bacterial strains. DC activation and cytokine production were accompanied by an early miR-146a upregulation followed by a strong miR-155 induction, which mainly controlled TNF $\alpha$ production. These results pave the way for further investigations into the nature of $H$. pylori antigens and the subsequently activated signaling pathways involved in the inflammatory response to $H$. pylori infection, the deregulation of which may likely contribute to gastric lymphomagenesis.

Keywords: Helicobacter pylori, dendritic cell, inflammation, TNF $\alpha$, microRNA

\section{INTRODUCTION}

Helicobacter pylori infection causes a chronic gastric mucosal inflammation, leading to peptic ulcer disease in $5-10 \%$ of the infected people, and to gastric adenocarcinoma and low-grade mucosa-associated lymphoid tissue (MALT) lymphoma in $1 \%$ of the cases. The pathogenesis of $H$. pylori infection has been linked to the strength of inflammation it promotes, which is correlated to the functionality of the cag pathogenicity island (PAI) in the bacteria (Censini et al., 1996). Gastric epithelial cells constitute the first line of defense against $H$. pylori; they produce interleukin (IL)-8, which promotes the recruitment of polynuclear cells. Immune cells including macrophages, dendritic cells (DC) and mucosa infiltrating lymphocytes take part in the innate and adaptative immune responses to the bacteria.

The pro-inflammatory properties of $H$. pylori strains have been mainly evaluated by measuring IL- 8 production of the AGS gastric epithelial cell line, but they deserve to be investigated on immune cells due to their orchestrated pro- and anti-inflammatory cytokine production in response to pathogens. In vivo the professional antigen-presenting DC were found to be recruited into the gastric mucosa and, due to the emission of dendrites inserting themselves between epithelial cell tight junctions, they may be able to interact with $H$. pylori (Rescigno et al., 2008; Shiu and Blanchard, 2013). Their role in H. pylori-induced inflammatory response needs to be clarified.
Host defense against pathogens requires the induction of appropriate innate immune responses, as excessive or inappropriate activation of the immune system can be deleterious to the organism. Therefore, various immune regulators, including microRNAs (miRNA), also take part in the immune responses (Baltimore et al., 2008). MiRNA received considerable attention because of their implication in maintaining homeostasis in fundamental biological processes in non-pathological states, and their deregulation in pathological states (Sonkoly and Pivarcsi, 2009). Changes in miRNA expression in response to bacterial infection have been reported, including $H$. pylori infection in the gastric mucosa, in gastric epithelial cells and in immune cells (Zhang et al., 2008; Fassi Fehri et al., 2010; Belair et al., 2011; Matsushima et al., 2011).

In the present study, primary human DCs were used to explore the inflammatory effectors induced by $H$. pylori strains. Two fully sequenced $H$. pylori strains were included for this purpose, i.e., strains B38 (Thiberge et al., 2010) and B45 (Lehours et al., 2011) which are cagPAI negative and cagPAI positive, respectively. In parallel to cytokine production, miRNA changes induced by $H$. pylori were analyzed; they included measuring miR-146 and miR-155, to which specific immunomodulatory functions in $H$. pylori infection were assigned after performing loss of function experiments. 


\section{MATERIALS AND METHODS ETHICS STATEMENT}

Written consent of hemochromatosis patients was obtained and approved by the French Ministry of Research and the French Aquitaine Limousin Blood Bank's (Bordeaux, France) ethics committee (approval number DC-2012-1648).

\section{In vitro GENERATION OF DCs}

All tissue culture reagents were purchased at Invitrogen (Marly Le Roi, France). Peripheral blood mononuclear cells (PBMC) from hemochromatosis patients were isolated by centrifugation on a Ficoll gradient and captured using magnetic CD14 microbeads (Miltenyi Biotec, Paris, France), according to the manufacturer's protocol. To generate immature DCs, monocytes were grown for 7 days in the presence of GM-CSF $(50 \mathrm{ng} / \mathrm{ml})$ and IL-4 $(25 \mathrm{ng} / \mathrm{ml})$ in RPMI-1640 medium supplemented with $10 \%$ heatdecomplemented fetal calf serum, $2 \mathrm{mM}$ of L-glutamine, and $50 \mu \mathrm{g} / \mathrm{ml}$ of vancomycin (Sandoz, Levallois Perret, France) at $37^{\circ} \mathrm{C}$ in a $5 \% \mathrm{CO}_{2}$ atmosphere.

\section{CULTURE OF H. pylori STRAINS}

$\mathrm{B} 38$ is a cagPAI negative strain, harboring the vacA $\mathrm{s} 2(\mathrm{i} 2) \mathrm{m} 2$ allele. B45 is a cagPAI positive strain, harboring the vacA s1(i1)m1 allele (Lehours et al., 2004b; Thiberge et al., 2010; Lehours et al., 2011). The P12 H. pylori strain or its $\Delta$ cagPAI isogenic deletion mutant (kindly provided by R. Peek, Vanderbilt University, Nashville, TN, USA) as well as 6 cagPAI positive and 6 cagPAI negative ulcer-associated strains (Lehours et al., 2004a) were also included. All strains were cultivated for $48 \mathrm{~h}$ at $37^{\circ} \mathrm{C}$ under microaerobic conditions $\left(5 \% \mathrm{O}_{2}\right)$ on selective agar consisting of $21.5 \mathrm{~g}$ of Wilkins Chalgren agar, $50 \mathrm{ml}$ of human blood, $10 \mu \mathrm{g} / \mathrm{ml}$ of vancomycin, $10 \mu \mathrm{g} / \mathrm{ml}$ of cefsulodin, $5 \mu \mathrm{g} / \mathrm{ml}$ of trimethoprim, and $10 \mu \mathrm{g} / \mathrm{ml}$ of amphotericin B.

\section{CO-CULTURES OF IMMATURE DCS AND $\boldsymbol{H}$. pylori STRAINS}

Immature DCs were washed once in PBS and plated onto 24well plastic plates at a density of $5.10^{5}$ cells per well in $1 \mathrm{ml}$ of RPMI-1640 growth medium. Bacteria were recovered from the agar plates using a swab and resuspended in RPMI-1640 growth medium at an optical density of 0.6 at $600 \mathrm{~nm}$, which corresponds to $3.10^{7} \mathrm{CFU} / \mathrm{ml}$. The bacteria were added to the DCs at the indicated multiplicity of infection (MOI) 1 and the cocultures were further incubated at $37^{\circ} \mathrm{C}$ in a $5 \% \mathrm{CO} 2$ atmosphere for $48 \mathrm{~h}$.

\section{DENDRITIC CELL ACTIVATION AND CYTOKINE ANALYSIS}

The DC surface activation markers CD40, CD80, CD83, CD86, and HLA-DR, as well as the following secreted cytokines, IL-2, IL-4, IL-6, IL-10, and TNF $\alpha$, were evaluated by flow cytometry using the Human Cytokine Bead Array Th1/Th2/Th17 Kit (Becton Dickinson, Le Pont de Claix, France). IL-8, IL-12, IL$1 \beta$, and IL-23 production was assessed by ELISA (Ready-SET-Go, eBioscience, San Diego, CA, USA). DCs alone or stimulated with Escherichia coli lipopolysaccharide (LPS) (100 ng/ml) (Sigma Aldrich, St Quentin Fallavier, France) were used as negative or positive controls for DC activation, respectively.

\section{DENDRITIC CELL APOPTOSIS}

The occurrence of DC apoptosis was assessed using annexin V staining and propidium iodure incorporation. DCs were centrifuged at $2000 \mathrm{rpm}$ for $10 \mathrm{~min}$ at $4^{\circ} \mathrm{C}$, washed once in cold PBS and resuspended in $25 \mu \mathrm{L}$ of $0.01 \mathrm{M}$ HEPES ( $\mathrm{pH} 7.4$ ), $0.14 \mathrm{M}$ $\mathrm{NaCl}$, and $0.25 \mathrm{mM} \mathrm{CaCl}_{2}$. The cells were labeled with $2.5 \mu \mathrm{L}$ of anti-annexin $\mathrm{V}$ antibody (eBioscience) and $1 \mu \mathrm{L}$ of propidium iodure $\left(1 \mathrm{mg} / \mathrm{mL}\right.$ ) (Sigma Aldrich) for $15 \mathrm{~min}$ at $4^{\circ} \mathrm{C}$ and analyzed by flow cytometry.

\section{OLIGONUCLEOTIDE TRANSFECTION}

Transfections were performed in 24-well plates using lipofectamin 2000 (Invitrogen) according to manufacturer's instructions, except that $5 \mu \mathrm{l} /$ well were used. DCs were transfected twice (at day -2 and then $2 \mathrm{~h}$ before infection) with $100 \mathrm{nM}$ of antisense miRNA (as155 or as146) or scrambled locked-nucleic-acid (LNA)-modified oligonucleotides (Table A1).

\section{RNA EXTRACTION AND mIRNA QUANTITATIVE RT-PCR}

DCs were collected in Eppendorf tubes and pelleted by centrifugation at $2000 \mathrm{rpm}$ for $5 \mathrm{~min}$ at room temperature. Total RNA was extracted from the DC pellet using a Trizol reagent (Invitrogen), according to manufacturer's instructions. RNA concentrations were determined by spectrophotometry (NanoDrop Technologies, Wilmington, DE, USA). RNA quality was determined on an Agilent 2100 Bioanalyzer (Agilent Technologies, Santa Clara, CA, USA). For miRNA quantitations, $250 \mathrm{ng}$ of total RNA were retrotranscribed using the miScript Reverse Transcription kit (Qiagen, Courtaboeuf, France) and qPCR was performed using a SYBr Green PCR kit and hsa-miR-155, hsa-miR-146a and SNOR25 specific primers (Qiagen), according to the manufacturer's instructions. The amplification profiles were measured on a Stratagene Mx3005P instrument (Life Technologies, Saint Aubin, France).

\section{STATISTICAL ANALYSIS}

Data were expressed as a ratio of fold induction compared to nonactivated DCs. For each experiment, all experimental conditions were tested three times and each experiment was conducted at least three times for each strain. Statistical analyses were done using the non-parametric Mann-Whitney test. A p-value of less than 0.05 was considered significant. All statistics were performed using SPSS 16.0F for Windows software (SPSS Inc., Chicago, IL, USA).

\section{RESULTS}

\section{DENDRITIC CELL ACTIVATION BY H. pylori}

The nature, the amount and the duration of the antigenic stimulation are important factors that can influence the inflammatory and molecular responses of DCs. Before infection, the immature DC phenotype (CD1a +, HLA-DR +, CD80 -, CD86 -, CD14 -, CD83-) was verified by flow cytometry (Figure A1). Our preliminary experiments showed that $H$. pylori at MOI 1 significantly activated DCs (Figure A2), with minimal apoptosis (less than 10\%) (Figure A3). 


\section{CYTOKINE PRODUCTION IN H. pylori-ACTIVATED DCs}

DCs activated by either the B38 or B45 strain at MOI 1 or by $E$. coli LPS secreted significant amounts of TNF $\alpha$, IL$1 \beta$, IL-6, IL-8, IL-10, IL-12, and IL-23, but not IL-2, IL-4, IL-17, TGF $\beta$, or INF $\gamma$ compared to non-activated DCs. $H$. pylori-activated DCs produced mainly TNF $\alpha$ (1500-2000 fold stimulated production over basal level), and in a decreasing order of stimulation, IL-6 (1000-fold), IL-10 (200-400 fold), IL-1 $\beta$ (150-fold), IL-23 (50-100 fold), IL-8 (10-fold) and IL-12 (5-fold) after $48 \mathrm{~h}$ of co-culture. The cytokine levels were low or nil in non-activated DC supernatants, except for IL-8 and IL-12 which were already secreted under basal conditions.

H. pylori-activated DCs produced the same cytokines as LPSactivated DCs, both qualitatively and quantitatively, except for IL-10 (Figure 1). This potent anti-inflammatory molecule was found at a significantly higher level upon stimulation by both $H$. pylori B38 and B45 than by LPS. Moreover, compared to E. coli LPS, IL-10 production was significantly induced by $H$. pylori B38 strain as early as $6 \mathrm{~h}$.
Analysis of cytokine production kinetics in $H$. pylori-activated DCs revealed the early, massive production of TNF $\alpha$ (Figure 1). $\mathrm{TNF} \alpha$ reached its maximal level as early as $6 \mathrm{~h}$ in the presence of LPS or the bacteria, and remained quite stable thereafter. IL-6 was maximally stimulated by E. coli LPS as early as $6 \mathrm{~h}$, and progressively with $H$. pylori (Figure 1).

There was generally no significant difference in the cytokine production between the two $H$. pylori strains, except for IL-23, a major cytokine involved in Th17 response, which was higher with B45 than with B38 (Figure 1). This difference could be attributed to the presence of the cagPAI in the B45 strain. To test this hypothesis, DCs were activated for $48 \mathrm{~h}$ by either $H$. pylori P12 strain or its isogenic cagPAI deletion mutant (Figure 1), and by 12 more $H$. pylori strains tested individually ( 6 cagPAI positive and 6 cagPAI negative) from our collection (Lehours et al., 2004a) (Figure 1). IL-23 secretion was significantly lower with the P12 mutant and the cagPAI negative strains than with the P12 wild type and the cagPAI positive strains confirming the positive influence of the cagPAI gene products on the secretion of this cytokine. IL-23 secretion started rather late following $H$. pylori infection, at $48 \mathrm{~h}$

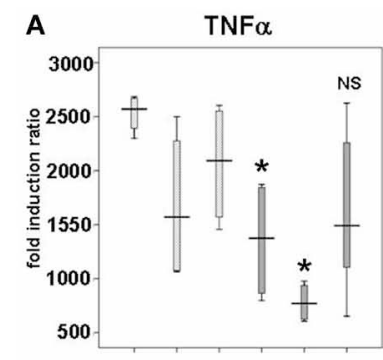

6h $24 h 48$ h 6 h $24 h 48 h$

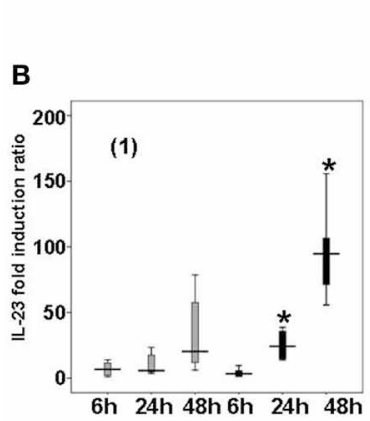

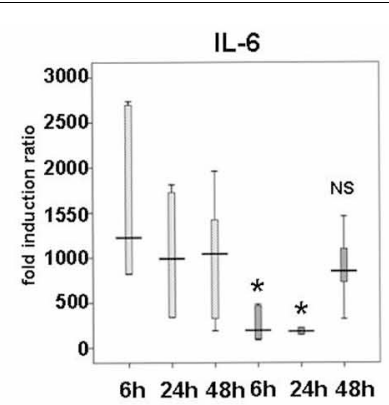
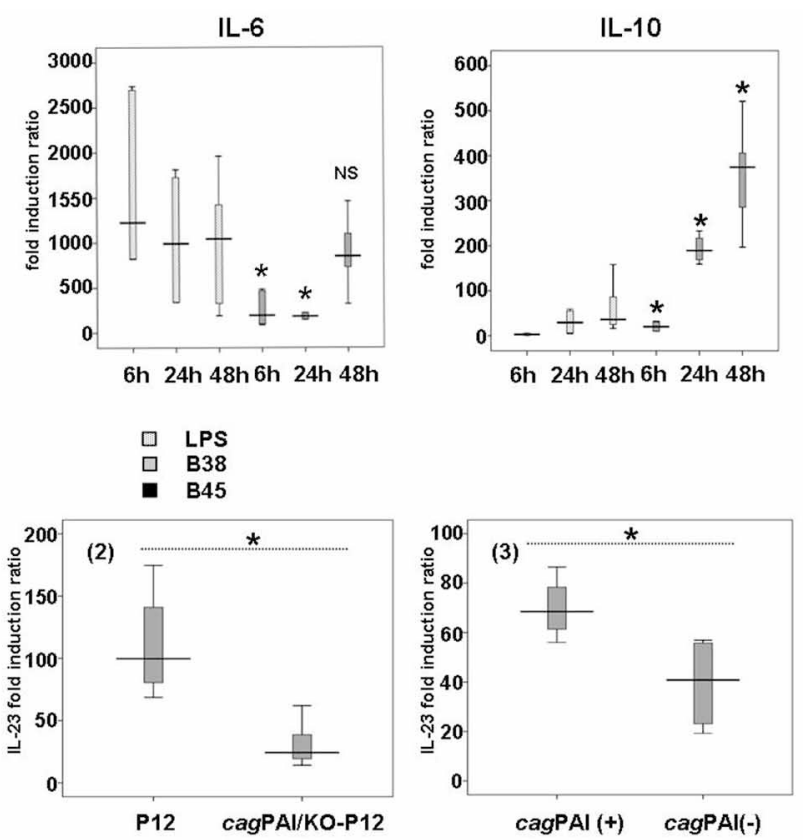

FIGURE 1 | Cytokine production in $\boldsymbol{H}$. pylori-activated dendritic cells.

(A) Kinetics of TNF $\alpha$, IL-6, and IL-10 secretion by E. coli LPS- or $H$. pylori-activated dendritic cells. DCs were either stimulated with E. coli LPS $(100 \mathrm{ng} / \mathrm{ml})$ or cocultivated with B38 $\mathrm{H}$. pylori strain at MOI 1 for 6,24 , or $48 \mathrm{~h}$. TNF $\alpha$, IL-6, and IL-10 secretion in the culture supernantants was evaluated by flow cytometry (as described in Materials and Methods). The horizontal bar across the box indicates the median and the capped bars indicate the minimum and maximum data values of fold induction ratio vs. DCs alone obtained for 6 independent experiments corresponding to 6 different donors. These results are representative of the results obtained for $\mathrm{H}$. pylori strain B45 for the same experiments. ${ }^{*}$ for $p<0.05$ and NS for $p>0.05$ compared to E. coli LPS at the corresponding time-point.

(B) Influence of the $H$. pylori cagPAl on the production of IL-23 by dendritic cells after $H$. pylori infection. (1) DCs were cocultured with B38 or B45
H. pylori strain at MOI 1 for 6,24 , or $48 \mathrm{~h}$. IL-23 levels in culture supernatants were measured by ELISA. The horizontal bar across the box indicates the median and the capped bars indicate the minimum and maximum data values of fold induction ratio vs. non-activated DCs, for 6 independent experiments for each strain and for 6 different donors. * for $p<0.05$ between the $H$. pylori strains B38 and B45 at the corresponding time-point. (2) DCs were cocultured for $48 \mathrm{~h}$ with $\mathrm{H}$. pylori strain P12 and its isogenic cagPAl mutant (KO-P12) at MOI 1 or (3) with 12 ulcer-associated $H$. pylori strains tested individually $(6$ cagPAl positive and 6 cagPAl negative). IL-23 levels in culture supernatants were measured by ELISA. The horizontal bar across the box indicates the median and the capped bars indicate the minimum and maximum data values of fold induction ratio vs. non-activated DCs, for 3 independent experiments for each group of strains and for three different donors ( ${ }^{*}$ if $p<0.05$ ). 
for B38 and $24 \mathrm{~h}$ for B45 (Figure 1). Finally, both LPS- and $H$. pylori-mediated activation displayed similar patterns of progressive production of IL-1 $\beta$, IL-8, and IL-12 over the time course (Figure A4).

\section{EXPRESSION OF miRNA IN $\boldsymbol{H}$. pylori-ACTIVATED DCs}

MiRNAs, differentially regulated in $H$. pylori-activated DCs as compared to immature DCs, were investigated using a $\mathrm{qPCR}$ array of 88 miRNA involved in human immunopathology. Among the screened miRNAs, 12 showed the highest induction levels (3-21 fold) and 13 the strongest repression (3-6 fold) (Table A1). Nevertheless, taking into account only those that were expressed the most upon induction (over 1/100 of average housekeeping genes), we identified miR-187, miR-155, miR-146a, let-7e, miR-29b, miR-34, miR-214, and miR-147 as being substantially upregulated following $H$. pylori infection. The relatively abundant miR-152, miR-195, miR-16, miR-30c, miR-223, miR126, miR-574-3p, miR-21, and miR125b were found to be the most repressed by the bacteria (Table 1 ).

Kinetic analyses of miR-146 and miR-155 expression in DCs co-cultured with either the B38 or the B45 strain at MOI 1 showed that both miRNAs were upregulated as early as $6 \mathrm{~h}$ post-infection and increased progressively thereafter (Figure 2A). Whereas miR$146 \mathrm{a}$ reached $50 \%$ of its maximal stimulation as early as $6 \mathrm{~h}$ post-infection, miR-155 was dramatically upregulated between 6 and $24 \mathrm{~h}$. Thus, at $48 \mathrm{~h}$ post-infection, miR-146 levels were increased by $5-10$ fold over the basal level, and miR-155 by 100-200 fold. The statistical analysis of 13 independent experiments showed no significant difference between the B38 and B45 strains in their ability to upregulate the miRNAs, since miR146a expression was enhanced by $4.06 \pm 0.47$ and $4.8 \pm 0.78$ fold ( $p=$ 0.927 ), and miR-155 by $84.03 \pm 15.87$ and $99.17 \pm 26.94$ fold $(p=0.224)$, respectively. This suggests that the miRNA response of $H$. pylori-activated DC was independent of the strain's cagPAI status. miR-146a was upregulated more by the H. pylori strains than by LPS, contrary to miR-155, which reached the same intensity after LPS stimulation as after co-culture with either of the H. pylori strains (Figure 2A). At $48 \mathrm{~h}$ post-infection, miR-146a upregulation was positively correlated with a MOI up to 40, whereas miR-155 upregulation peaked at MOI 1-5 and decreased at higher ones (Figure 2B). The global results indicate that miR146a and miR-155 upregulations take part in the DC immune response to $H$. pylori, independently of their cagPAI status, with miR-146a upregulation preceding the massive miR-155 biosynthesis.

In order to investigate the importance of these miRNAs in the regulation of cytokine production upon infection, their mature forms were functionally inhibited using antisense oligonucleotides (or their scrambled controls), which were introduced into immature DCs using lipofectamin prior to the LPS or H. pylori challenge. Both miR-146a and miR-155 knockdown had little influence on the LPS- or $H$. pylori-mediated upregulation of DC surface activation markers, suggesting that neither one was required for this process (data not shown). Anti-miR-146 antisense oligonucleotides totally prevented LPS- or H. pyloritriggered miR-146 upregulation (Figure 3A) and had no influence on the level of miR-155 induction, and vice versa, showing
Table 1 | miRNA differentially regulated in $\boldsymbol{H}$. pylori B38-activated dendritic cells.

\begin{tabular}{|c|c|c|}
\hline $\begin{array}{l}\text { Up-regulated } \\
\text { miRNA }\end{array}$ & $\begin{array}{l}\text { Fold change } \\
\text { upon infection }\end{array}$ & $\begin{array}{l}\text { Relative level in } \\
\text { infected cells }\end{array}$ \\
\hline hsa-miR-187 & 21.0756 & 0.0515 \\
\hline hsa-miR-155 & 13.4310 & 2.5491 \\
\hline hsa-miR-198 & 7.6079 & 0.0023 \\
\hline hsa-miR-135b & 6.5319 & 0.0049 \\
\hline hsa-miR-299-3p & 5.5693 & 0.0020 \\
\hline hsa-miR-451 & 4.8821 & 0.0052 \\
\hline hsa-miR-146a & 4.8149 & 21.8566 \\
\hline hsa-let-7e & 4.7816 & 2.4284 \\
\hline hsa-miR-184 & 4.3094 & 0.0016 \\
\hline hsa-miR-29b & 4.2797 & 0.1216 \\
\hline hsa-miR-34a & 4.1339 & 0.7738 \\
\hline hsa-miR-214 & 4.1626 & 0.0110 \\
\hline hsa-miR-206 & 3.1987 & 0.0046 \\
\hline hsa-miR-147 & 3.0898 & 0.3276 \\
\hline hsa-miR-302a & 3.0262 & 0.0015 \\
\hline $\begin{array}{l}\text { Downregulated } \\
\text { miRNA }\end{array}$ & $\begin{array}{l}\text { Fold change } \\
\text { upon infection }\end{array}$ & $\begin{array}{l}\text { Relative } \\
\text { initial level }\end{array}$ \\
\hline hsa-miR-409-3p & 0.1728 & 0.0904 \\
\hline hsa-miR-152 & 0.2070 & 0.2897 \\
\hline hsa-miR-150 & 0.2113 & 0.0333 \\
\hline hsa-miR-195 & 0.2584 & 145.2606 \\
\hline hsa-miR-16 & 0.2675 & 202.6014 \\
\hline hsa-miR-30c & 0.3051 & 12.6626 \\
\hline hsa-miR-223 & 0.3115 & 143.2608 \\
\hline hsa-miR-126 & 0.3248 & 1.6386 \\
\hline hsa-miR-574-3p & 0.3270 & 1.3218 \\
\hline hsa-miR-21 & 0.3293 & 1307.4137 \\
\hline hsa-miR-203 & 0.3362 & 0.0168 \\
\hline hsa-mir-125b & 0.3529 & 1.9219 \\
\hline
\end{tabular}

One $\mu \mathrm{g}$ of total RNA from DCs cultured for $48 \mathrm{~h}$ in the absence or presence of $\mathrm{H}$. pylori B38 at MOI 1 was retro-transcribed using the RT2 miRNA First Strand Kit (Qiagen, Courtaboeuf, France). The first strand reaction was mixed with RT2 SYBR Green QPCR mix and distributed onto PCR array plates containing primers for 88 miRNA involved in human immunopathology (SABioscience, Qiagen) according to manufacturer's protocol. The amplification profiles were measured on a Stratagene Mx3005P instrument (Life Technologies, Saint Aubin, France). Data were analyzed by the $C_{t}$ method (Livak and Schmittgen, 2001), using the average $C_{t}$ of the housekeeping RNA for normalization. Data are expressed as fold induction compared to non-activated DCs in the medium lane. For each miRNA, the level relative to the mean expression of housekeeping genes is shown in the right lane, in order to assess which miRNA may be expressed at levels high enough to be relevant (highlighted).

the efficiency of antisenses to inhibit miRNA expression, most likely by sequestering them. This also suggests that miR-146a and miR-155 expression may not be correlated in this cell system. Nevertheless, in response to $H$. pylori, two cytokines were clearly affected by this treatment (Figure 3B). First, in comparison to scrambled oligonucleotide-treated cells, TNF $\alpha$ production at $48 \mathrm{~h}$ was induced to a $50 \%$ greater extent in anti-miR-155-treated 


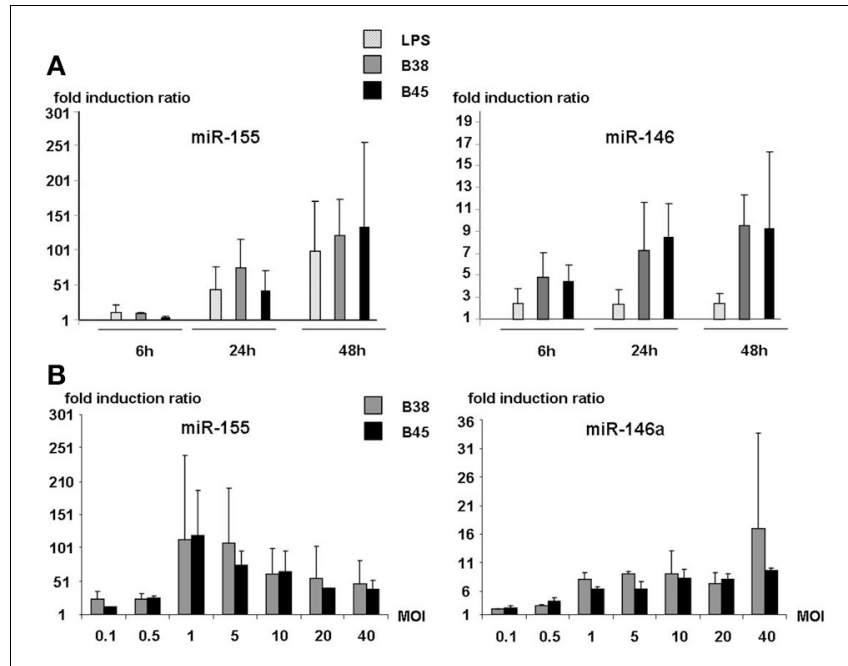

FIGURE 2 | MOI dependence and kinetic analyses of miR-146a and miR155 expression in activated dendritic cells. (A) DCs were either stimulated with E. coli LPS or cocultured with $\mathrm{H}$. pylori strains B38 or B45 at $\mathrm{MOI} 1$ for 6,24 , or $48 \mathrm{~h}$. (B) DCs were cocultured with $H$. pylori strains $\mathrm{B} 38$ or $\mathrm{B} 45$ at $\mathrm{MOls}$ ranging from 0.1 to 40 for $48 \mathrm{~h}$. For both experiments, miRNA levels were determined by RT-qPCR. Data is presented as the fold induction ratio (mean + standard deviation of duplicate) of activated vs. non-activated DCs and is representative of one experiment out of 3 .

cells notably upon $H$. pylori infection, whereas it was weakly impaired $(\leq 20 \%)$ by anti-miR-146. Second, anti-miR-146 treatment clearly impaired IL-10 production upon infection, whereas anti-miR-155 had no significant effect. miR-146a or miR-155 knockdown did not affect the cytokine response to LPS. This treatment did not alter IL- $1 \beta$ or IL- 8 production and only weakly affected that of other cytokines after $H$. pylori challenge (Figure A5).

\section{DISCUSSION}

In this manuscript, we aimed at analyzing the initial steps of the immune response to $H$. pylori strains. We therefore developed an ex vivo co-culture cell system, in which we showed that $H$. pylori strains were able to activate primary human DCs and promote strong proinflammatory cytokine and miRNA responses. Although most of the observed effects were independent of the $H$. pylori cagPAI status, the cagPAI positive strain specifically upregulated IL-23, most likely to orientate DCs to promote a Th17 response.

Numerous articles have been published on the interaction between $H$. pylori and DCs, however, with a huge heterogeneity in the bacterial strains, MOI and experimental conditions (viable/sonicated/paraformaldehyde-treated bacteria) (Guiney et al., 2003; Hafsi et al., 2004; Kranzer et al., 2004, 2005; Kao et al., 2006; Mitchell et al., 2007; Rad et al., 2009; Andres et al., 2010; Kao et al., 2010; Fehlings et al., 2012). Our data were obtained using primary human DCs from several donors. All experiments were repeated with at least three different donors in order to ensure the reliability of the results. Significant productions of several cytokines (TNF $\alpha$, IL-1 $\beta$, IL-6, IL-8, IL-10, IL-12, and IL-23) were observed in $H$. pylori-activated DCs, TNF $\alpha$ and

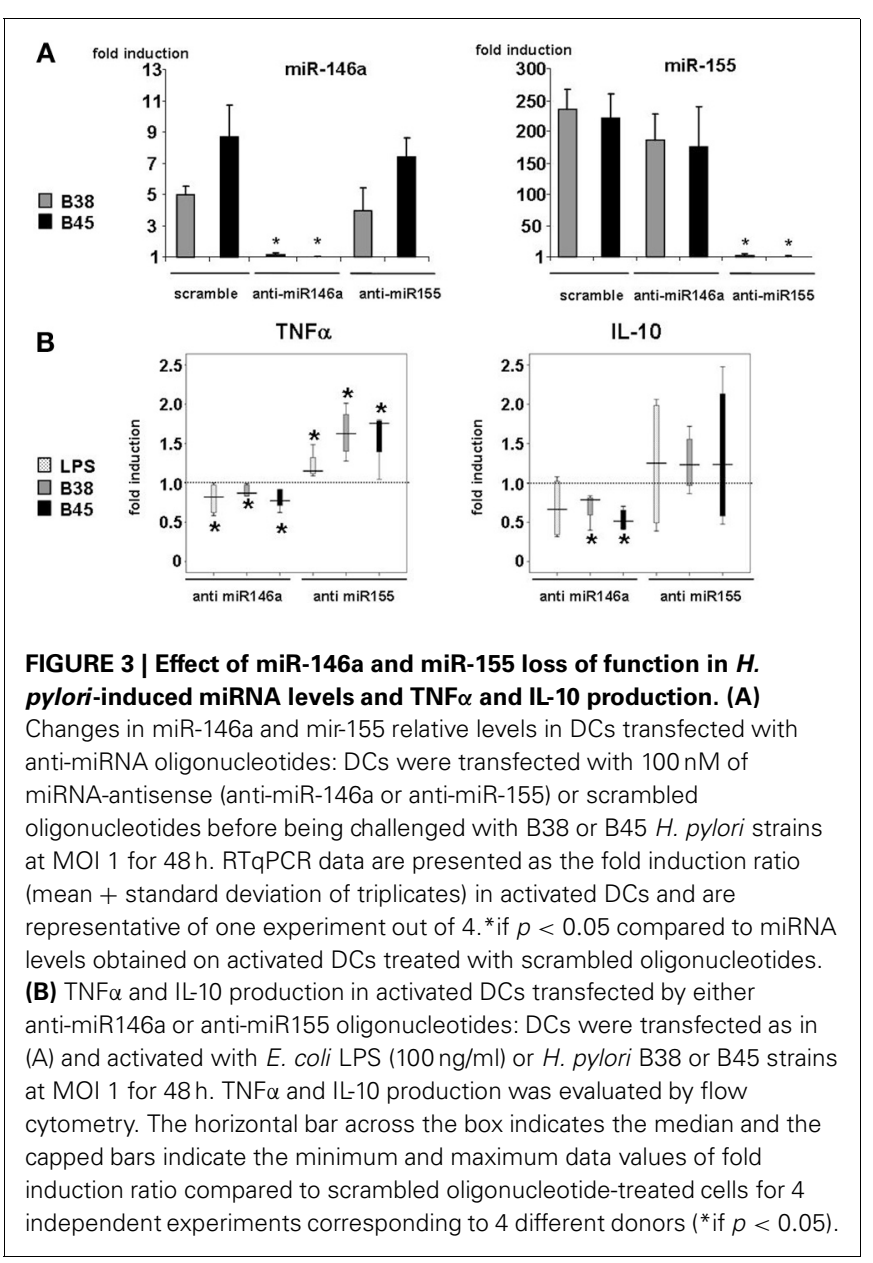

IL- 6 being produced at the highest levels. In vivo, TNF $\alpha$ contributes to monocyte maturation after recruitment, whereas IL-6 supports the transition between the early stages of the infection and the sustained mononuclear influx into the infected gastric mucosa. Early production of TNF $\alpha$ and IL-6 upon LPS stimulation reflects the intrinsic property of E. coli LPS to trigger TLR4 signaling pathways, a property that is not shared by $H$. pylori LPS (Rad et al., 2009). Delayed secretion of TNF $\alpha$ and IL-6 by H. pylori-activated DCs as compared to LPS-activated ones may depend on bacterial DNA and RNA recognition by endosomal TLR9 and TLR8, respectively (Rad et al., 2009), a later process when compared to the recognition of pathogen associated-motifs by surface TLRs. At later time points ( 24 and $48 \mathrm{~h}$ ), a switch in the inflammatory response occurred with an accumulation over time of IL-6, IL-10, IL-23, and IL-1 $\beta$, without any significant induction of TGF $\beta$. The late IL-10 and IL-12 production by $H$. pylori-activated DCs may coincide in vivo with their homing in lymph nodes (Kranzer et al., 2004). IL-10 was secreted at a higher level after DC activation by $H$. pylori than by E. coli LPS, in accordance with recent data, which showed that $H$. pylori interactions with both TLR2 and the lectin DC-SIGN contributed to an antiinflammatory environment via the release of IL-10 (Rad et al., 2009; Fehlings et al., 2012). IL-12, which plays a role in the differentiation of naive $\mathrm{T}$ cells toward Th1 cells (Pellicano et al., 
2007), was the least produced cytokine upon DC activation. In the present study, the high IL-10 and TNF $\alpha$ levels secreted by activated DCs could be responsible for the low IL-12 secretion due to their ability to inhibit its production (Langenkamp et al., 2000). In addition, IL-23 was the only cytokine dependent on the strain's cagPAI status. This result is still a matter of debate. Indeed several papers show that cagPAI could influence in vitro IL-23 release by DCs (Khamri et al., 2009; Tanaka et al., 2010). However, others argue that cagPAI does not regulate cytokine production in DCs cocultured with H. pylori (Kao et al., 2010; Horvath et al., 2012). Previous data from experiments on human gastric biopsies infected with $H$. pylori indicate that myeloid DCs co-localize with IL-23 and IL-17-producing, infiltrating lymphocytes (Khamri et al., 2010); one could therefore hypothesize that the H. pylori B45 strain may be able to induce a Th17 response, likely mediated by the cagPAI status. As IL-23 also plays an important role in sustaining Th17 responses in addition to acting on lymphoid cells to induce IL-17 (Shi et al., 2010; Hitzler et al., 2013), signaling pathways involved in this phenomenon deserve further investigation.

In parallel to the cytokine response profile, miR-155 and miR-146a were co-upregulated most intensely and invariably in activated DCs, independently of the cagPAI status of the bacterial strain. These two miRNA were previously expressed at high levels in H. pylori-infected gastric mucosa (Liu et al., 2010; Lario et al., 2012). Our results clearly show that the extent of their upregulation as well as their kinetics and MOI-dependence did not evolve in parallel with the time-course of $H$. pylori-activated DCs. MiR-146 upregulation takes part in the early immune program activated in DCs by $H$. pylori, as it reached $50 \%$ of its maximal 10 fold stimulation as early as $6 \mathrm{~h}$ post-infection, while miR-155 was induced at a striking rate $24 \mathrm{~h}$ post-infection, reaching 200 fold the stimulated levels at $48 \mathrm{~h}$. The massive induction of miR-155 in DCs over the time-course of their activation by both LPS and H. pylori is consistent with previous findings (O'Connell et al., 2007; Tili et al., 2007; Martinez-Nunez et al., 2009). Indeed, miR-155 can be induced by pathogen-associated ligands via TLR-, NF- $\kappa \mathrm{B}-$, and MyD 88-dependent pathways or by several cytokines such as IL-1 $\beta$ (Ceppi et al., 2009) and TNF $\alpha$ (Tili et al., 2007) which are both likely to sustain the high miR155 biosynthesis induced in LPS-stimulated or $H$. pylori-infected DCs. An alternative miR-155 activation by bacterial peptidoglycan sensing via the cytoplasmic NOD2 receptor has been reported (Schulte et al., 2013), which may participate to the massive miR155 induction. Contrary to miR-146, miR-155 was induced via a biphasic profile according to the MOI, suggesting that at a high MOI, the increasing level of some inflammatory cytokines might negatively regulate miR-155 expression. As the antiinflammatory cytokine IL-10 was found to inhibit LPS-induced miR-155 upregulation without affecting miR-146a (McCoy et al., 2010), it is likely that $H$. pylori-stimulated IL-10 production is responsible for the decreased miR-155 upregulation at high MOIs.

The role of miR-146 and miR-155 in the innate immune responses was deduced from the identification of their respective targets. As miR-146a targets and silences TNF-receptorassociated factor and IL- $1 \beta$ receptor-associated kinase mRNAs, which are key adapter molecules in the TLR/ NFKB pathway, the role of miR-146a upregulation in response to pathogens was shown to moderate TLR-triggering of the NFKB pathway via a negative feedback loop, thus avoiding overproduction of proinflammatory IL-1 $\beta$ and TNF $\alpha$ cytokines (Taganov et al., 2006; Nahid et al., 2009; Lu et al., 2010). A similar immune regulatory function was assigned to miR-155 which targets several gene transcripts of the NF- $\kappa$ B pathway (FADD, Ripk1, IKK, and NIK), as well as the immune cell transcription factor PU, Src homology 2 domain-containing inositol-5-phosphatase (SHIP) and CCAAT enhancer-binding protein beta (C/EBPbeta) (Rodriguez et al., 2007; Tili et al., 2007; Costinean et al., 2009; Schulte et al., 2013). In addition, miR-155 also stabilizes the TNF $\alpha$ mRNA (Tili et al., 2007; Semaan et al., 2011), suggesting that simultaneous anti- and pro-inflammatory effects of miR-155 most likely contribute to the fine-tuning of the TNF-mediated inflammation. We assessed the role of miR-146 and miR-155 in the DC cytokine response to $H$. pylori using specific antisenses to each miRNA, which inhibit their silencing function by competition with their binding sites on mRNA targets. Thus, the most noticeable effect of miR-155 loss of function in our cell system was an enhanced $\mathrm{TNF} \alpha$ production by $H$. pylori, an effect consistent with the immunomodulatory role assigned to miR-155 upregulation in response to microbial stimuli (O'Connell et al., 2007; Rodriguez et al., 2007; Ceppi et al., 2009; Martinez-Nunez et al., 2009). Enhanced TNF $\alpha$ response to $H$. pylori in the absence of miR-155 may also be facilitated by the downregulation of miR$125 \mathrm{~b}$ which we observed in our microarray (Table 1), and which directly targets TNF $\alpha$ (Tili et al., 2007). In our miR-146 loss of function experiment, no cytokine response was markedly altered with the exception of IL-10. The impaired production of this anti-inflammatory cytokine in response to $H$. pylori is concordant with the previously established immunomodulatory role of miR146 upon infection, but it was not accompanied by an enhanced production of inflammatory cytokines in anti-miR-146-treated cells as expected. A possible explanation for the decreased IL-10 response to $H$. pylori in the absence of miR-146 could be that miR-146 loss of function unmasks the regulatory effects of other miRNAs: for instance, let-7e, which directly targets IL-10 (Schulte et al., 2011) was upregulated in H. pylori-activated DCs (Table 1) and may subsequently negatively regulate IL-10. The differences in the effects of miR-146 and miR-155 knockdown, which stress the prominent role of miR-155 in $H$. pylori-activated DCs, could be related to different functional specializations of these two seemingly co-induced miRNAs, as recently reported in LPSstimulated murine macrophages (Schulte et al., 2013); miR-146 responded to sub-inflammatory stimuli to prevent TLR activation, and miR-155 responded to pro-inflammatory stimuli as a global limiter of the inflammatory response. Our experimental conditions established a TNF $\alpha$-filled, pro-inflammatory environment in cultured DCs, and thus preferentially elicited miR-155 functions.

miR-146a and miR-155 expressions may be of special interest in $H$. pylori-mediated immune pathologies, because they are associated with NFKB activation, a pathway strongly activated during $H$. pylori infection and in $H$. pylori-driven MALT lymphoma. High expression of miR-146a was associated with 
chronic inflammatory diseases (Sonkoly and Pivarcsi, 2009) and miR-155 represents an important element in B cell lymphoma development (Costinean et al., 2006), indicating that alterations in the fine-tuning of innate immune responses by miRNAs may contribute to inflammatory disorders. Other miRNAs, which are differentially regulated in $H$. pylori-activated DCs, deserve further investigation; among them, miR-187, which was strongly upregulated in the H. pylori-activated DCs, could control IL-10-driven anti-inflammatory responses (Rossato et al., 2012).

In conclusion, the co-culture cell system presented here allowed the identification of pro- and anti-inflammatory effectors in response to $H$. pylori and revealed the influence of the cagPAI on the immune responses. These important findings pave the way for further investigations on the nature of $H$. pylori antigens

\section{REFERENCES}

Andres, S., Schmidt, H. M., Mitchell, H., Rhen, M., Maeurer, M., and Engstrand, L. (2010). Helicobacter pylori defines local immune response through interaction with dendritic cells. FEMS Immunol. Med. Microbiol. 61, 168-178. doi: 10.1111/j.1574-695X.2010.00761.x

Baltimore, D., Boldin, M. P., O'Connell, R. M., Rao, D. S., and Taganov, K. D. (2008). MicroRNAs: new regulators of immune cell development and function. Nat. Immunol. 9, 839-845. doi: 10.1038/ni.f.209

Belair, C., Baud, J., Chabas, S., Sharma, C. M., Vogel, J., Staedel, C., et al. (2011). Helicobacter pylori interferes with an embryonic stem cell micro RNA cluster to block cell cycle progression. Silence 2, 7. doi: 10.1186/1758-907X-2-7

Censini, S., Lange, C., Xiang, Z., Crabtree, J. E., Ghiara, P., Borodovsky, M., et al. (1996). cag, a pathogenicity island of Helicobacter pylori, encodes type I-specific and disease-associated virulence factors. Proc. Natl. Acad. Sci. U.S.A. 93, 14648-14653. doi: 10.1073/pnas.93.25.14648

Ceppi, M., Pereira, P. M., DunandSauthier, I., Barras, E., Reith, W., Santos, M. A., et al. (2009). MicroRNA-155 modulates the interleukin-1 signaling pathway in activated human monocyte-derived dendritic cells. Proc. Natl. Acad. Sci. U.S.A. 106, 2735-2740. doi: 10.1073/pnas.0811073106

Costinean, S., Sandhu, S. K., Pedersen, I. M., Tili, E., Trotta, R., Perrotti, D., et al. (2009). Src homology 2 domain-containing inositol5-phosphatase and CCAAT enhancer-binding protein beta are targeted by miR-155 in B cells of Emicro-MiR-155 transgenic mice. Blood 114, 1374-1382. doi: 10.1182/blood-2009-05-220814
Costinean, S., Zanesi, N., Pekarsky, Y., Tili, E., Volinia, S., Heerema, N., et al. (2006). Pre-B cell proliferation and lymphoblastic leukemia/highgrade lymphoma in $\mathrm{E}(\mathrm{mu})$-miR155 transgenic mice. Proc. Natl. Acad. Sci. U.S.A. 103, 7024-7029. doi: 10.1073/pnas.0602266103

Fassi Fehri, L., Koch, M., Belogolova, E., Khalil, H., Bolz, C., Kalali, B., et al. (2010). Helicobacter pylori induces miR-155 in $\mathrm{T}$ cells in a cAMP-Foxp3-dependent manner. PLoS ONE 5:e9500. doi: 10.1371/journal.pone.0009500

Fehlings, M., Drobbe, L., Moos, V., Renner Viveros, P., Hagen, J., Beigier-Bompadre, M., et al. (2012). Comparative analysis of the interaction of Helicobacter pylori with human dendritic cells, macrophages, and monocytes. Infect. Immun. 80, 2724-2734. doi: 10.1128/IAI.00381-12

Guiney, D. G., Hasegawa, P., and pylori preferentially induces interleukin 12 (IL-12) rather than IL-6 or IL-10 in human dendritic cells. Infect. Immun. 71, 4163-4166. doi: 10.1128/IAI.71.7.4163-4166.2003

Hafsi, N., Voland, P., Schwendy, S., Rad, R., Reindl, W., Gerhard, M., et al. (2004). Human dendritic cells respond to Helicobacter pylori, promoting NK cell and Th1-effector responses in vitro. J. Immunol. 173, 1249-1257.

Hitzler, I., Kohler, E., Engler, D. B., Yazgan, A. S., and Muller, A. (2013). The role of Th cell subsets in the control of Helicobacter infections and in $\mathrm{T}$ cell-driven gastric immunopathology. Front. Immunol. 3:142. doi: 10.3389/fimmu.2012.00142 Cope, V. A., and Algood, H. M. (2012). IL-23 contributes to control of chronic Helicobacter pylori Cole, S. P. (2003). Helicobacter

Horvath, D. J. Jr., Washington, M. K.,

and the subsequently activated signaling pathways involved in the inflammatory response to $H$. pylori infection.

\section{ACKNOWLEDGMENTS}

This work was supported by grants from La Ligue contre le Cancer (Committee of Dordogne, France), the Structure Fédérative de Recherche TransBiomed (Bordeaux, France) and the Société Nationale Française de Gastroentérologie. Anaïs Hocès de la Guardia received funding from the French Ministry of Research. The authors thank Jonathan Ferrand (Center for Innate Immunity and Infectious Disease, Monash Institute of Medical Research, Clayton, Australia), Patrick Blanco (CNRS UMR 5164, Bordeaux, France) for fruitful discussions and Lindsay Mégraud for English revision of the manuscript.

infection and the development of $\mathrm{T}$ helper responses in a mouse model. Front. Immunol. 3:56. doi: 10.3389/fimmu.2012.00056

Kao, J. Y., Rathinavelu, S., Eaton, K. A., Bai, L., Zavros, Y., Takami, M., et al. (2006). Helicobacter pylori-secreted factors inhibit dendritic cell IL-12 secretion: a mechanism of ineffective host defense. Am. J. Physiol. Gastrointest. Liver Physiol. 291, G73-G81. doi: 10.1152/ajpgi.00139.2005

Kao, J. Y., Zhang, M., Miller, M. J., Mills, J. C., Wang, B., Liu, M., et al. (2010). Helicobacter pylori immune escape is mediated by dendritic cell-induced Treg skewing and Th17 suppression in mice. Gastroenterology 138, 1046-1054. doi: 10.1053/j.gastro.2009.11.043

Khamri, W., Walker, M. M., Clark, P., Atherton, J. C., Thursz, M. R., Bamford, K. B., et al. (2009). Helicobacter pylori stimulates dendritic cells to induce interleukin-17 expression from CD4+ T lymphocytes. Infect. Immun. 78, 845-853. doi: 10.1128/IAI.00524-09

Khamri, W., Walker, M. M., Clark, P., Atherton, J. C., Thursz, M. R., Bamford, K. B., et al. (2010). Helicobacter pylori stimulates dendritic cells to induce interleukin-17 expression from CD4+ T lymphocytes. Infect. Immun. 78, 845-853. doi: 10.1128/IAI.00524-09

Kranzer, K., Eckhardt, A., Aigner, M., Knoll, G., Deml, L., Speth, C., et al. (2004). Induction of maturation and cytokine release of human dendritic cells by Helicobacter pylori. Infect. Immun. 72, 4416-4423. doi: 10.1128/IAI.72.8.4416-4423.2004

Kranzer, K., Sollner, L., Aigner, M., Lehn, N., Deml, L., Rehli, M., et al. (2005). Impact of Helicobacter pylori virulence factors and compounds on activation and maturation of human dendritic cells.
Infect. Immun. 73, 4180-4189. doi: 10.1128/IAI.73.7.4180-4189.2005

Langenkamp, A., Messi, M., Lanzavecchia, A., and Sallusto, F. (2000). Kinetics of dendritic cell activation: impact on priming of TH1, TH2 and nonpolarized T cells. Nat. Immunol. 1, 311-316. doi: 10.1038/79758

Lario, S., Ramirez-Lazaro, M. J., Aransay, A. M., Lozano, J. J., Montserrat, A., Casalots, A., et al. (2012). microRNA profiling in duodenal ulcer disease caused by Helicobacter pylori infection in a Western population. Clin. Microbiol. Infect. 18, E273-E282. doi: 10.1111/j.1469-0691.2012.03849.x

Lehours, P., Dupouy, S., Bergey, B., Ruskone-Foumestraux, A., Delchier, J. C., Rad, R., et al. (2004a). Identification of a genetic marker of Helicobacter pylori strains involved in gastric extranodal marginal zone B cell lymphoma of the MALT-type. Gut 53, 931-937. doi: 10.1136/gut. 2003.028811

Lehours, P., Menard, A., Dupouy, S., Bergey, B., Richy, F., Zerbib, F., et al. (2004b). Evaluation of the association of nine Helicobacter pylori virulence factors with strains involved in low-grade gastric mucosa-associated lymphoid tissue lymphoma. Infect. Immun. 72, 880-888. doi: 10.1128/IAI.72.2.880-888.2004

Lehours, P., Vale, F. F., Bjursell, M. K., Melefors, O., Advani, R., Glavas, S., et al. (2011). Genome sequencing reveals a phage in Helicobacter pylori. MBio 2:e00239-11. doi: 10.1128/mBio.00239-11

Liu, Z., Xiao, B., Tang, B., Li, B., Li, N., Zhu, E., et al. (2010). Up-regulated microRNA-146a negatively modulate Helicobacter pylori-induced inflammatory response in human gastric epithelial 
cells. Microbes Infect. 12, 854-863. doi: 10.1016/j.micinf.2010.06.002

Livak, K. J., and Schmittgen, T. D. (2001). Analysis of relative gene expression data using real-time quantitative PCR and the 2(-Delta Delta $\mathrm{C}(\mathrm{T})$ ) Method. Methods 25, 402-408. doi: 10.1006/meth.2001.1262

Lu, L. F., Boldin, M. P., Chaudhry, A., Lin, L. L., Taganov, K. D., Hanada, T., et al. (2010). Function of miR-146a in controlling Treg cell-mediated regulation of Th1 responses. Cell 142, 914-929. doi: 10.1016/j.cell.2010.08.012

Martinez-Nunez, R. T., Louafi, F., Friedmann, P. S., and SanchezElsner, T. (2009). MicroRNA-155 modulates the pathogen binding ability of dendritic cells (DCs) by down-regulation of DC-specific intercellular adhesion molecule-3 grabbing non-integrin (DC-SIGN). J. Biol. Chem. 284, 16334-16342. doi: 10.1074/jbc.M109.011601

Matsushima, K., Isomoto, H., Inoue, N., Nakayama, T., Hayashi, T., Nakayama, M., et al. (2011). MicroRNA signatures in Helicobacter pylori-infected gastric mucosa. Int. J. Cancer 128, 361-370. doi: 10.1002/ijc.25348

McCoy, C. E., Sheedy, F. J., Qualls, J. E., Doyle, S. L., Quinn, S. R., Murray, P. J., et al. (2010). IL10 inhibits miR-155 induction by toll-like receptors. J. Biol. Chem. 285, 20492-20498. doi: 10.1074/jbc. M110.102111

Mitchell, P., Germain, C., Fiori, P. L., Khamri, W., Foster, G. R., Ghosh, S., et al. (2007). Chronic exposure to Helicobacter pylori impairs dendritic cell function and inhibits Th1 development. Infect. Immun. 75, 810-819. doi: 10.1128/IAI.00228-06

Nahid, M. A., Pauley, K. M., Satoh, M., and Chan, E. K. (2009). miR-146a is critical for endotoxininduced tolerance: implication in innate immunity. J. Biol. Chem. 284, 34590-34599. doi: 10.1074/jbc.M109.056317

O'Connell, R. M., Taganov, K. D., Boldin, M. P., Cheng, G., and Baltimore, D. (2007). MicroRNA-155 is induced during the macrophage inflammatory response. Proc. Natl. Acad. Sci. U.S.A. 104, 1604-1609. doi: 10.1073/pnas.0610731104

Pellicano, A., Sebkova, L., Monteleone, G., Guarnieri, G., Imeneo, M., Pallone, F., et al. (2007). Interleukin12 drives the Th1 signaling pathway in Helicobacter pylori-infected human gastric mucosa. Infect. Immun. 75, 1738-1744. doi: 10.1128/IAI.01446-06

Rad, R., Ballhorn, W., Voland, P., Eisenacher, K., Mages, J., Rad, L., et al. (2009). Extracellular and intracellular pattern recognition receptors cooperate in the recognition of Helicobacter pylori. Gastroenterology 136, 2247-2257. doi: 10.1053/j.gastro.2009.02.066

Rescigno, M., Lopatin, U., and Chieppa, M. (2008). Interactions among dendritic cells, macrophages, and epithelial cells in the gut: implications for immune tolerance. Curr. Opin. Immunol. 20, 669-675. doi: 10.1016/j.coi.2008.09.007

Rodriguez, A., Vigorito, E., Clare, S., Warren, M. V., Couttet, P., Soond, D. R., et al. (2007). Requirement of bic/microRNA-155 for normal immune function. Science 316, 608-611. doi: 10.1126/science.1139253

Rossato, M., Curtale, G., Tamassia, N., Castellucci, M., Mori, L., Gasperini, S., et al. (2012). IL-10-induced microRNA-187 negatively regulates TNF-alpha, IL-6, and IL-12p40 production in TLR4-stimulated monocytes. Proc. Natl. Acad. Sci. U.S.A. 109, E3101-E3110. doi: 10.1073/pnas.1209100109

Schulte, L. N., Eulalio, A., Mollenkopf, H. J., Reinhardt, R., and Vogel, J. (2011). Analysis of the host microRNA response to Salmonella uncovers the control of major cytokines by the let-7 family. EMBO J. 30, 1977-1989. doi: 10.1038/emboj.2011.94

Schulte, L. N., Westermann, A. J., and Vogel, J. (2013). Differential activation and functional specialization of miR-146 and miR-155 in innate immune sensing. Nucleic Acids Res. 41, 542-553. doi: 10.1093/nar/gks1030

Semaan, N., Frenzel, L., Alsaleh, G., Suffert, G., Gottenberg, J. E., Sibilia, J., et al. (2011). miR-346 controls release of TNF-alpha protein and stability of its mRNA in rheumatoid arthritis via tristetraprolin stabilization. PLOS ONE 6:e19827. doi: $\quad 10.1371 /$ journal.pone. 0019827

Shi, Y., Liu, X. F., Zhuang, Y., Zhang, J. Y., Liu, T., Yin, Z., et al. (2010). Helicobacter pylori-induced Th17 responses modulate Th1 cell responses, benefit bacterial growth, and contribute to pathology in mice. J. Immunol. 184, 5121-5129. doi: 10.4049/jimmunol. 0901115

Shiu, J., and Blanchard, T. G. (2013). Dendritic cell function in the host response to Helicobacter pylori infection of the gastric mucosa. Pathog. Dis. 67, 46-53. doi: 10.1111/2049-632X.12014

Sonkoly, E., and Pivarcsi, A. (2009). microRNAs in inflammation. Int. Rev. Immunol. 28, 535-561. doi: 10.3109/08830180903208303

Taganov, K. D., Boldin, M. P., Chang, K. J., and Baltimore, D. (2006). NF-kappaB-dependent induction of microRNA miR-146, an inhibitor targeted to signaling proteins of innate immune responses. Proc. Natl. Acad. Sci. U.S.A. 103, 12481-12486. doi: 10.1073/pnas. 0605298103

Tanaka, H., Yoshida, M., Nishiumi, S., Ohnishi, N., Kobayashi, K., Yamamoto, K., et al. (2010). The CagA protein of Helicobacter pylori suppresses the functions of dendritic cell in mice. Arch. Biochem. Biophys. 498, 35-42. doi: 10.1016/j.abb.2010.03.021

Thiberge, J. M., Boursaux-Eude, C., Lehours, P., Dillies, M. A., Creno, S., Coppee, J. Y., et al. (2010). From array-based hybridization of Helicobacter pylori isolates to the complete genome sequence of an isolate associated with MALT lymphoma. BMC Genomics 11:368. doi: 10.1186/1471-2164-11-368

Tili, E., Michaille, J. J., Cimino, A., Costinean, S., Dumitru, C. D., Adair, B., et al. (2007). Modulation of miR-155 and miR-125b levels following lipopolysaccharide/TNFalpha stimulation and their possible roles in regulating the response to endotoxin shock. J. Immunol. 179, 5082-5089.

Zhang, Z., Li, Z., Gao, C., Chen, P., Chen, J., Liu, W., et al. (2008). miR21 plays a pivotal role in gastric cancer pathogenesis and progression. Lab. Invest. 88, 1358-1366. doi: 10.1038/labinvest.2008.94

Conflict of Interest Statement: The authors declare that the research was conducted in the absence of any commercial or financial relationships that could be construed as a potential conflict of interest.

Received: 21 May 2013; accepted: 30 July 2013; published online: 20 August 2013. Citation: Hocès de la Guardia A, Staedel C, Kaafarany I, Clément A, Roubaud Baudron C, Mégraud $F$ and Lehours $P$ (2013) Inflammatory cytokine and microRNA responses of primary human dendritic cells cultured with Helicobacter pylori strains. Front. Microbiol. 4:236. doi: 10.3389/fmicb.2013.00236

This article was submitted to Microbial Immunology, a section of the journal Frontiers in Microbiology.

Copyright (๑) 2013 Hocès de la Guardia, Staedel C, Kaafarany, Clément, Roubaud Baudron, Mégraud and Lehours. This is an open-access article distributed under the terms of the Creative Commons Attribution License (CC BY). The use, distribution or reproduction in other forums is permitted, provided the original author(s) or licensor are credited and that the original publication in this journal is cited, in accordance with accepted academic practice. No use, distribution or reproduction is permitted which does not comply with these terms. 


\section{APPENDIX}

Table A1 | MiRNA microarray data in uninfected DC (control) and DCs infected for $48 \mathrm{~h}$ by $H$. pylori B38 strain at MOI 1.

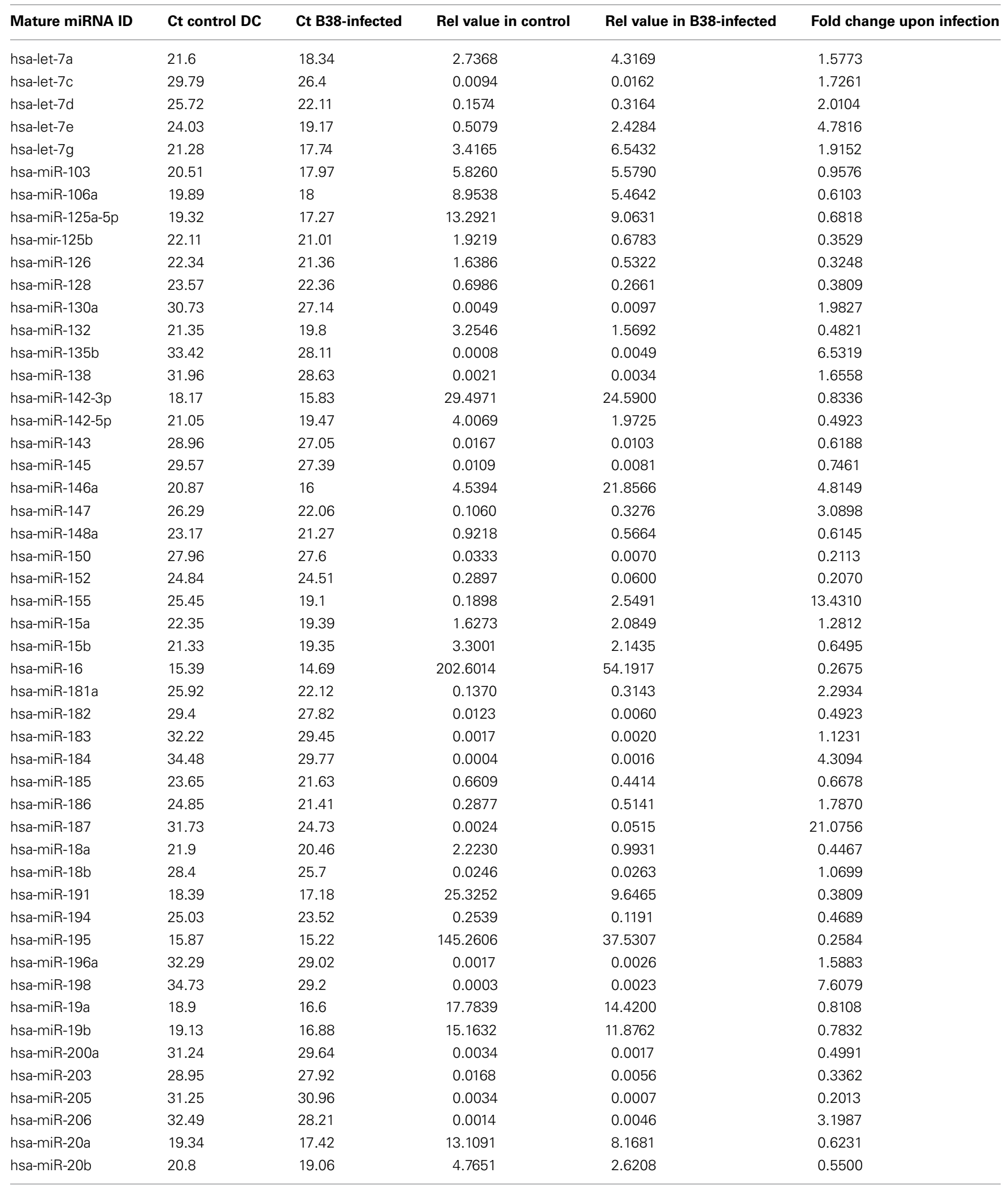


Table A1 | Continued

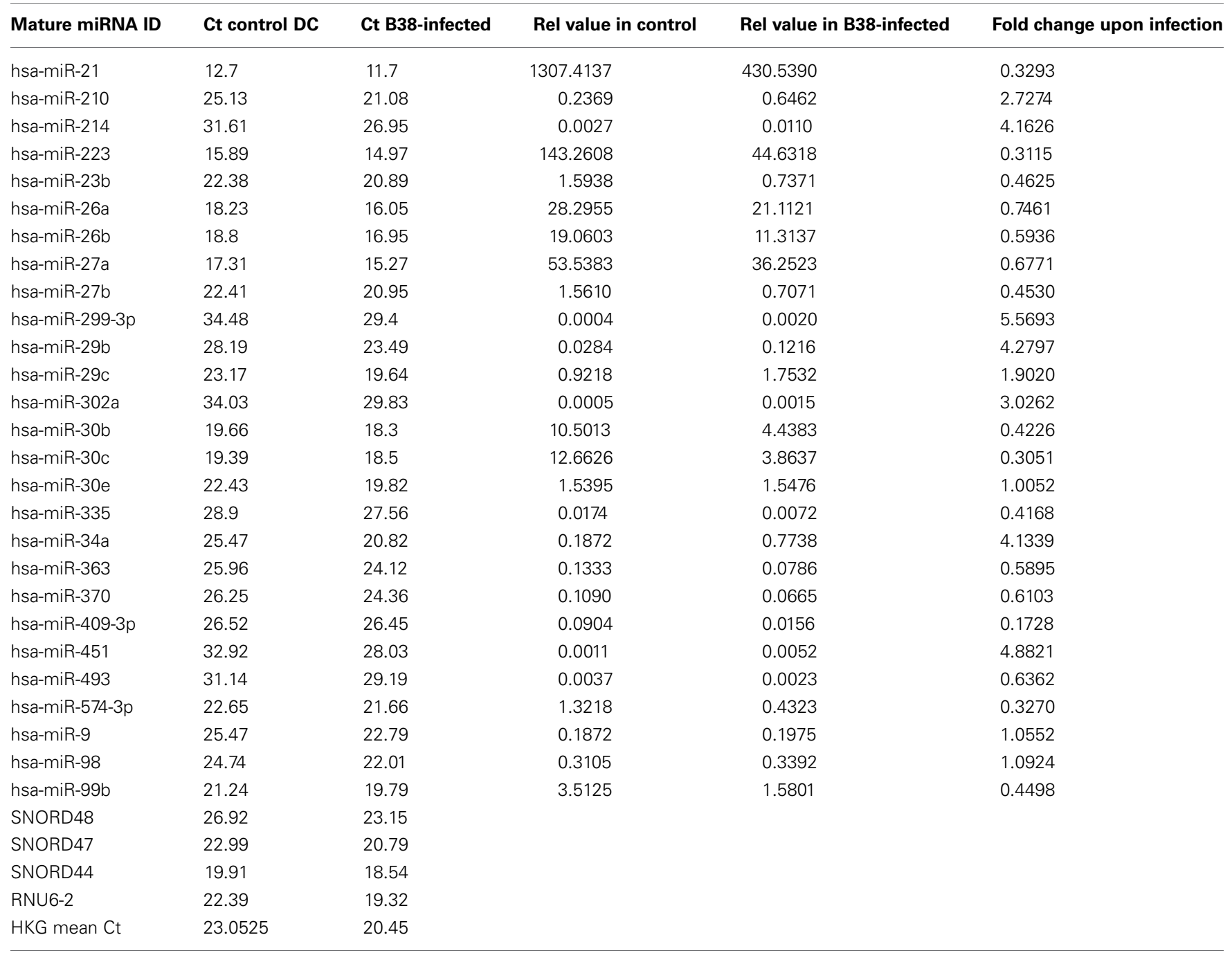

One $\mu \mathrm{g}$ of total RNA from DCs cultured for $48 \mathrm{~h}$ in the absence or presence of H. pylori B38 at MOI 1 was retro-transcribed using the RT2 miRNA First Strand Kit (Qiagen, Courtaboeuf, France). The first strand reaction was mixed with RT2 SYBR Green qPCR mix and distributed onto PCR array plates containing primers for 88 miRNA involved in human immunopathology (SABioscience, Qiagen) according to the manufacturer's protocol. The amplification profiles were measured on a Stratagene Mx3005P instrument (Life Technologies, Saint Aubin, France). The relative value for each miRNA was calculated by the $\triangle C t$ method taking account the mean Ct for housekeeping genes (HKG). The fold induction of each miRNA corresponds to the ratio of its relative value in B38-infected DCs versus its relative value in control DCs. 

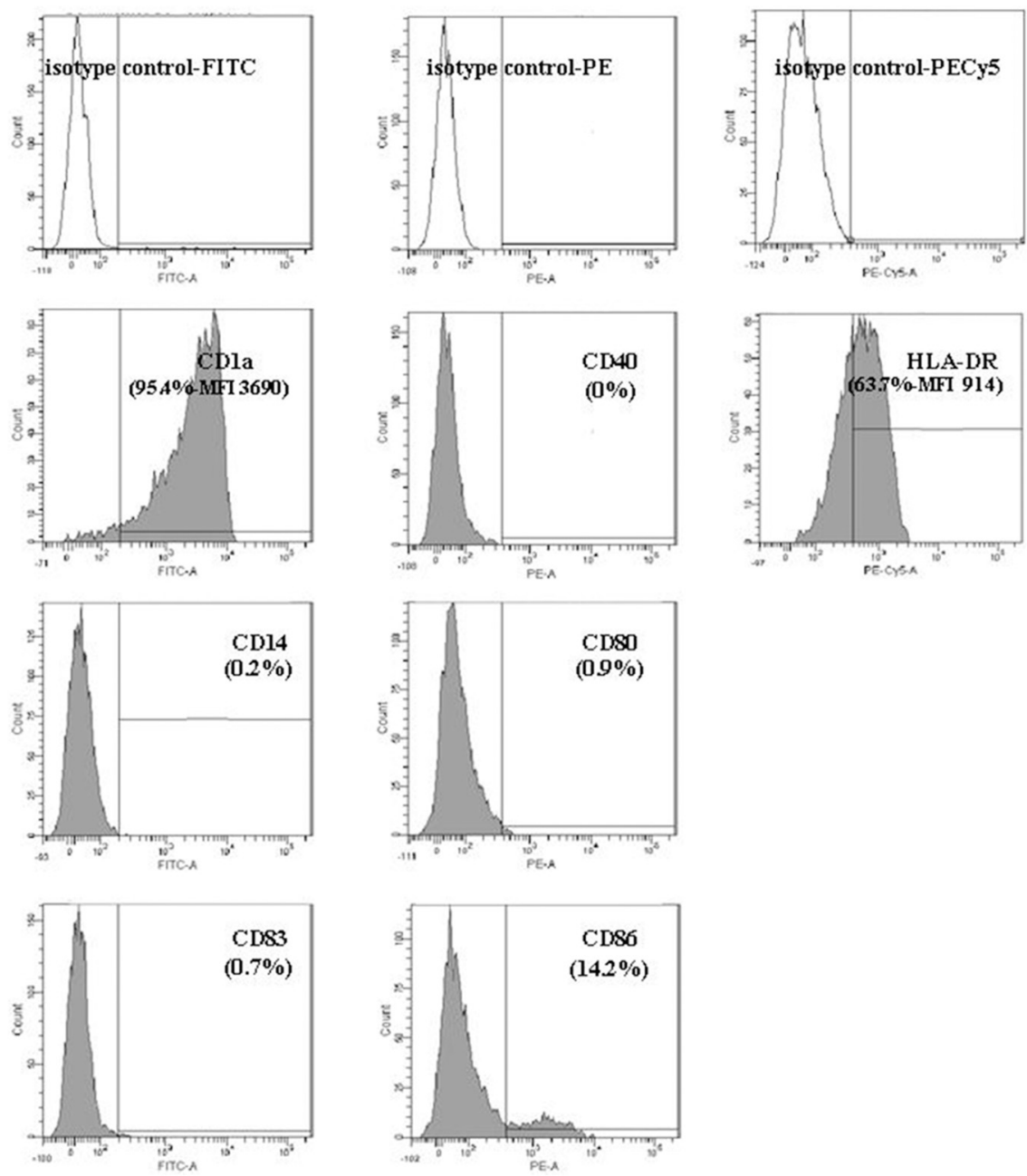

FIGURE A1 | Characterization of the immature state of dendritic cells after 7 days of differentiation with GM-CSF and IL- 4 as determined by flow cytometry. After 7 days of culture in the presence of GM-CSF and IL-4, DCs were labeled with the following antibodies: CD14-FITC, CD1a-FITC, CD40-PE, CD80-PE, CD83-FITC, CD86-PE, and HLA-DR-PECy5. They were analyzed by flow cytometry using a Canto II cytometer (Becton Dickinson, Le Pont de Claix, France). The percentages of positively labeled cells were determined after subtraction of the isotype control values (black histograms on the top of the figure) and are presented in gray histograms for each surface marker. In mature DCs, CD40, CD80, CD83, and CD86 were low in accordance with a non-activated stage. A high proportion of DCs expressed the CD1a and HLA-DR molecules. For each activation marker data [percentage of positive cells + mean fluorescence intensity (MFI)] are indicated. One representative experiment out of 13 is shown. 


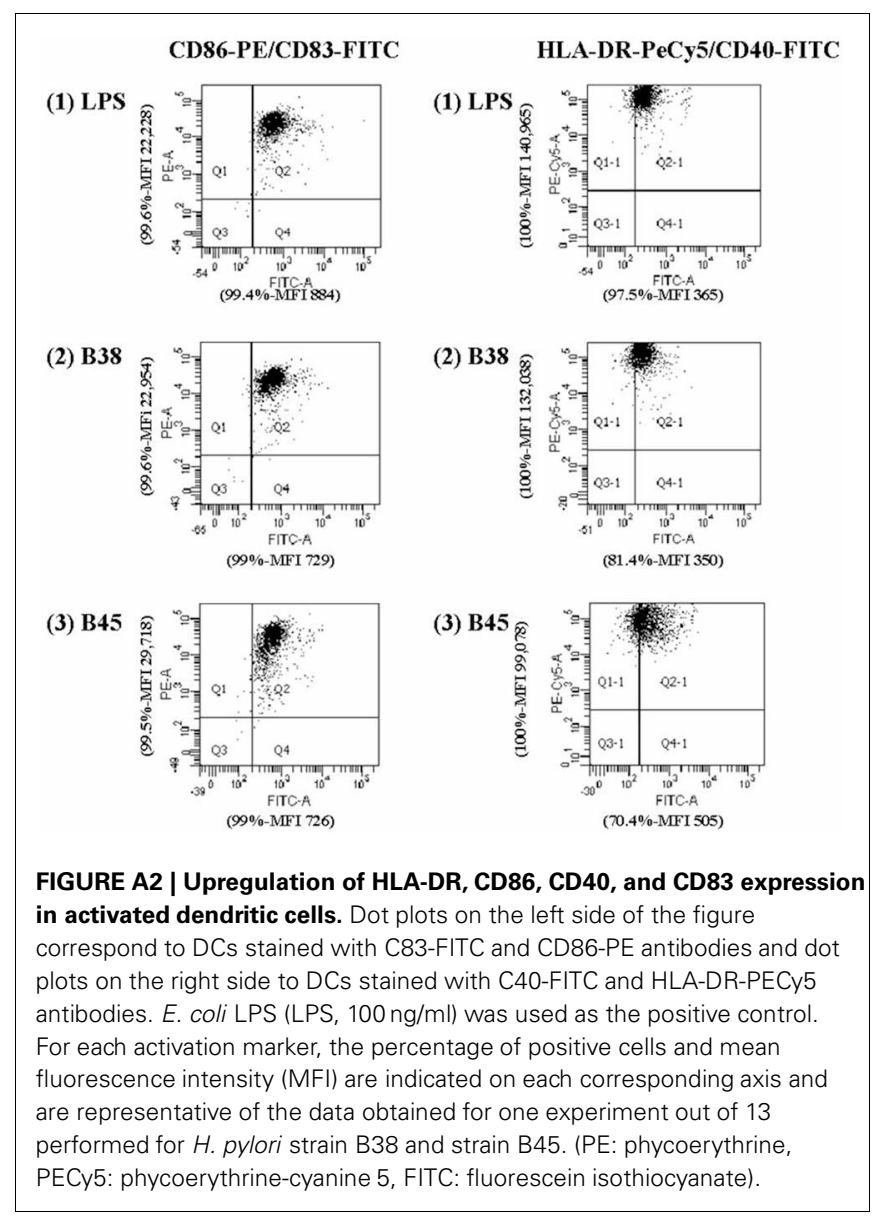

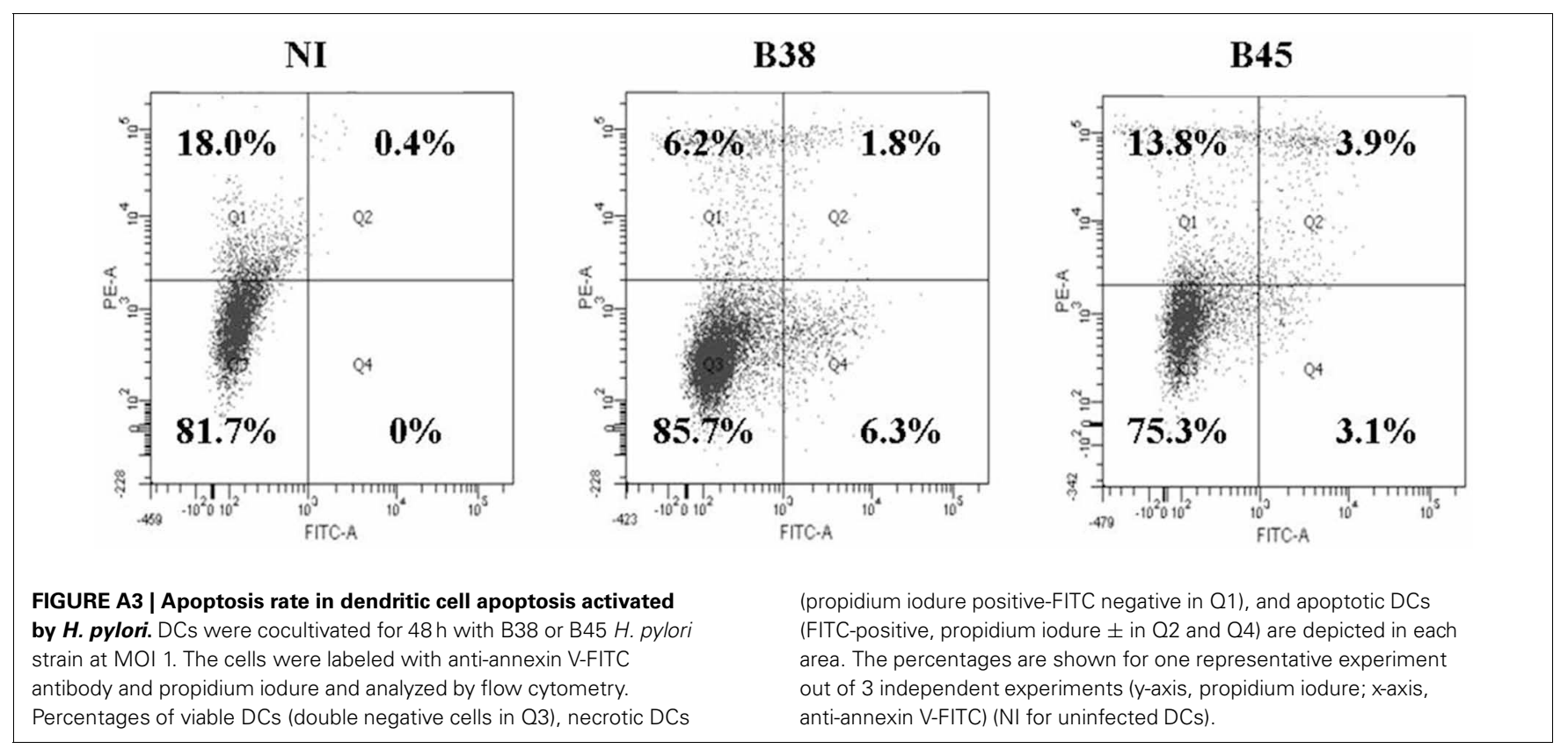




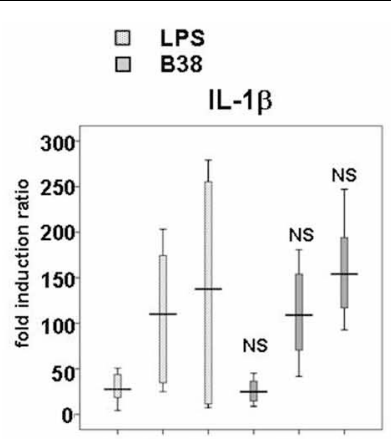

6h $24 h 48$ h 6 h $24 h 48 h$

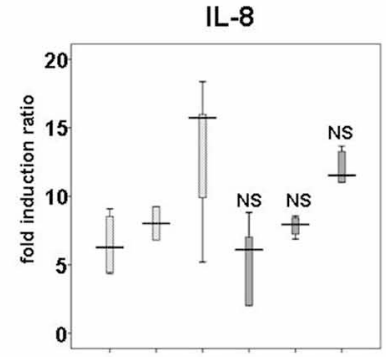

6h $24 \mathrm{~h} 48 \mathrm{~h} 6 \mathrm{~h} 24 \mathrm{~h} 48 \mathrm{~h}$

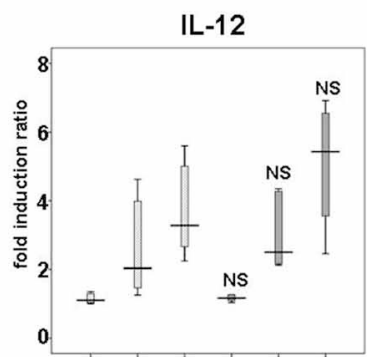

6h $24 \mathrm{~h} 48 \mathrm{~h} 6 \mathrm{~h} 24 \mathrm{~h} 48 \mathrm{~h}$
FIGURE A4 | Kinetics of IL-1 $\beta$, IL-8 and IL-12 production by $E$. coli LPS- or $\boldsymbol{H}$. pylori-activated dendritic cells. DCs were either stimulated with E. coli LPS $(100 \mathrm{ng} / \mathrm{mL})$ or cocultivated with $H$. pylori B38 strain at MOI 1 for 6,24 , or $48 \mathrm{~h}$. IL-1 $\beta$, IL-8, and IL-12 secretion levels were assessed by ELISA (as described in Material and Methods). The horizontal bar across the box indicates the median and the capped bars indicate the minimum and maximum data values of fold induction ratio vs. DCs alone obtained for 6 independent experiments corresponding to 6 different donors. These results are representative of those obtained for $H$. pylori B45 strain-activated DC performed in parallel during the same experiments. NS for $p>0.05$ compared to E. coli LPS-activated DC at the corresponding time-point.

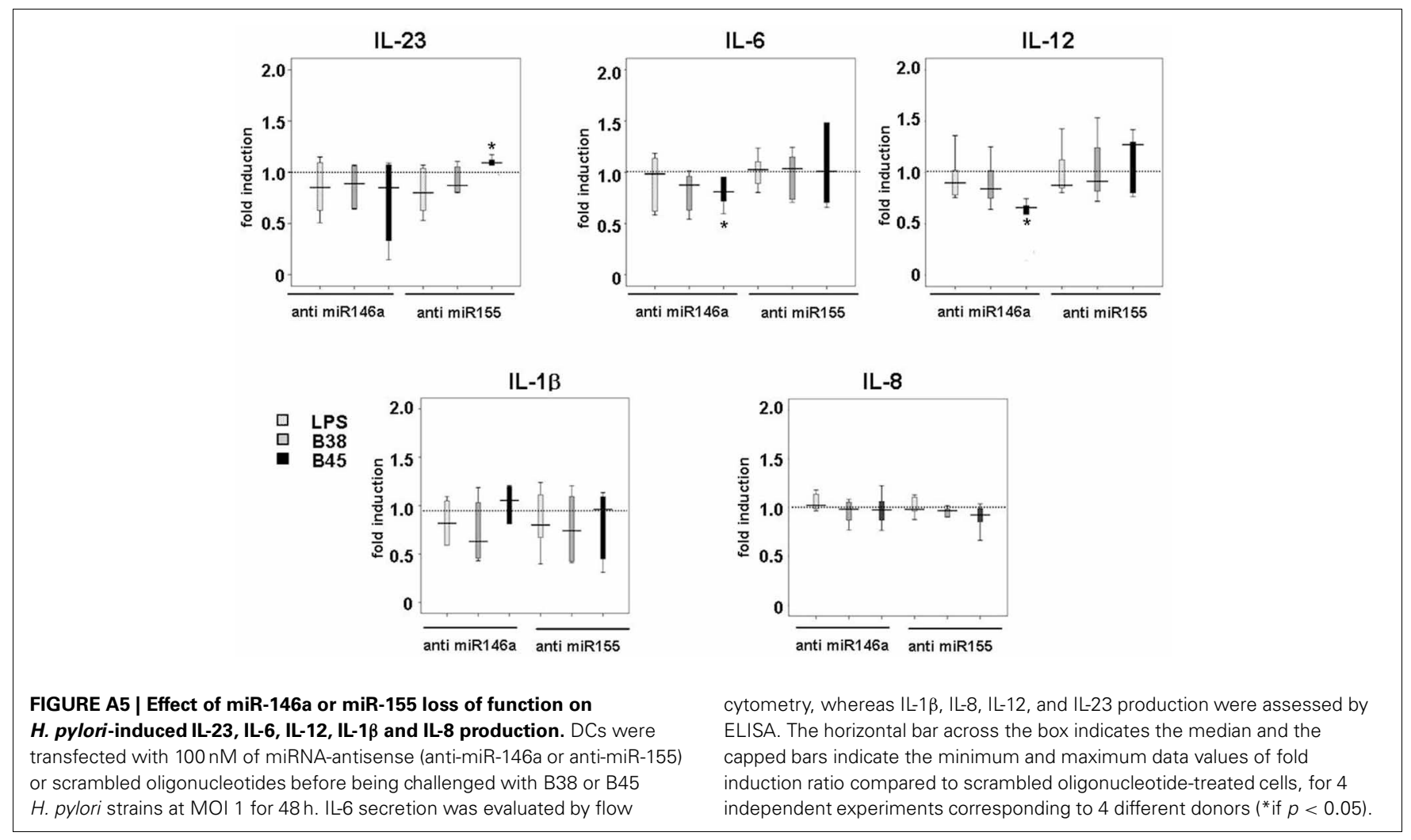

